\title{
SISTEMA PRISIONAL DO ESTADO DO RIO DE JANEIRO: A EDUCAÇÃO COMO PROCESSO PARA RESSOCIALIZAÇÃO
}

\section{ARTIGO ORIGINAL}

OLIVEIRA, Kely Bernardes de ${ }^{1}$, SANTOS, Lailson Bizerra dos ${ }^{2}$, MOURA, Vitória Carolina Oliveira de ${ }^{3}$

OLIVEIRA, Kely Bernardes de. SANTOS, Lailson Bizerra dos. MOURA, Vitória Carolina Oliveira de. Sistema Prisional Do Estado Do Rio De Janeiro: A Educação Como Processo Para Ressocialização. Revista Científica Multidisciplinar Núcleo do Conhecimento. Ano 06, Ed. 06, Vol. 14, pp. 31-44. Junho de 2021. ISSN: 2448-0959, Link de acesso: https://www.nucleodoconhecimento.com.br/administracao/educacaocomo-processo,

DOI:

10.32749/nucleodoconhecimento.com.br/administracao/educacao-como-processo

\section{RESUMO}

O sistema penitenciário brasileiro se tornou conhecido por sua ineficiência. O Estado do Rio de Janeiro não consegue gerir de forma eficaz, não sendo capaz de garantir acesso aos direitos mais básicos dos encarcerados. $O$ presente trabalho tem por finalidade mostrar as dificuldades e benefícios da escola no Sistema Prisional no que tange ao processo de ressocialização. A problemática que será trabalhada é: O que faz da escola uma forma de ressocializar para além de suas dimensões pedagógicas, auxiliando o presidiário a vivenciar melhor a sua pena? Produzida de forma qualitativa, apresenta objetivo de cunho exploratório. Após a reflexão que nos levou à elaboração deste artigo, foi possível entender melhor o escopo da ressocialização a partir da interferência escolar na vida dos presidiários. Mostrando também a relevância no sentido de prepará-los para a retomada à vida em sociedade, transformando pensamentos e atitudes. E como um ônus, a escola no sistema prisional ainda faz

\footnotetext{
${ }^{1}$ Graduanda em Administração Pública.

${ }^{2}$ Graduando em Administração Pública.

${ }^{3}$ Graduanda em Direito.
} 
com que pessoas obtenham ensino e capacitação, tanto os que não terminaram ou até mesmo os que não haviam começado sua alfabetização do lado de fora.

Palavras-chave: escola prisional, ressocialização, Rio de Janeiro.

\section{INTRODUÇÃO}

O contexto do trabalho que se inicia é a educação oferecida no sistema prisional carioca. Pretende trazer muito assunto para discutir, pela amplitude de todas as questões envolvidas. De acordo com a literatura estudada, o nosso sistema penitenciário é conhecido pela sua ineficiência, tudo porque o Estado não consegue gerir de forma a permitir que os presos tenham ao menos integridade enquanto cumprem as suas penas. Segundo Diorio (2017), o que acontece é que eles não têm sequer o direito de receber a possibilidade de uma preparação para que possam ser reintegrados à sociedade.

Em partes, como assevera Julião (2003) a violência dentro dos presídios é causada pela falta de investimento financeiro, que faz com que não haja a menor dignidade nestas celas com péssima infraestrutura, mas também há a questão das drogas, doentes mentais em presídios comuns, superlotação, condições precárias de higiene, dentre tantas outras coisas. Por este motivo é que o objetivo geral deste trabalho é tratar da oferta da escola dentro do espaço prisional; além de especificamente mostrar que ressocializar deve ser o primeiro pensamento quando um preso adentra a escola, uma vez que a educação liberta, em seu sentido mais amplo. Outro objetivo específico é mostrar que o sistema prisional em questão é omisso, assim como o Estado que não faz valer as leis, o que atrapalha demais o trabalho da escola.

O procedimento metodológico será a análise qualitativa do material lido para que após essa leitura crítica e exploratória se possa dissertar a respeito do que se encontrou pertinente para o tema em questão. Como resultado encontrado, o principal foi que a escola é de suma relevância no sentido de ressocializar, além de ser uma grande oportunidade para que ele recupere o tempo que perdeu em sua escolarização. 
Quanto à estrutura do trabalho, primeiramente irá se verificar a importância da presença da escola na área prisional e o quanto ela contribui para a reintegração social do indivíduo, valor como instrumento de tratamento penitenciário. Depois será possível verificar a legislação pertinente, mostrando que o preso tem ali um direito e não um favor. Será mostrado ainda que é lamentável que a gestão penitenciária não seja parceira da escola, dificultando muitas vezes o trabalho. Concluindo então que tal fato muitas vezes se torna um entrave a mais a vencer para que os indivíduos em privação de liberdade tenham a possibilidade de voltar ao convívio social com mais chances de estarem ressocializados de verdade e poderem ingressar mais uma vez, ou até pela primeira vez no mercado de trabalho.

\section{DESENVOLVIMENTO}

\subsection{AS ESCOLAS PRISIONAIS NO RIO DE JANEIRO}

A década de 60 trouxe a primeira escola prisional para o estado do Rio de Janeiro. Nesta época não chamavam de escola, mas sim de Classes de Cooperação (CCs). Tratava-se de um grupo de professores que iam até as prisões para dar aulas aos presos, a cargo da administração da Secretaria Estadual de Educação. Inicialmente, possuía acesso para até $4^{\underline{a}}$ série. Não tinham estrutura para o funcionamento da escola, eram pequenos espaços improvisados para que pudessem atender a demanda educacional de forma básica e muitas vezes até precárias.

Até o ano de 2007, os Colégios Estaduais que funcionavam dentro de Unidades Prisionais e Socioeducativas estavam ligados a Coordenadoria Regional na qual a escola/presídio estivesse geograficamente localizada. Assim sendo, as escolas do Complexo de Gericinó ficaram vinculadas à Coordenadoria Regional Metropolitana IV. Os colégios estaduais que funcionavam no bairro do Estácio, o Complexo Penitenciário da Frei Caneca, estavam vinculados à Coordenadoria Regional Metropolitana VI. Em São Cristóvão, no Presídio do Galpão da Quinta, estava vinculado à Coordenadoria Regional Metropolitana III, e assim por diante. Ainda nesse ano, a Resolução SEEDUC no 3528/2007 vinculou os colégios à Assessoria do 
Gabinete do Secretário de Educação sob a coordenação de uma Coordenadoria Especial. Com isso, as escolas nas Unidades Prisionais tomaram um avanço, isto porque tanto as escolas Socioeducativas como as escolas em Prisões através da COESP, ficaram ligadas ao Gabinete do Secretário de Estado de Educação proporcionado uma celeridade na tomada de decisão e ações concernentes a estas escolas.

No ano de 2010 foi idealizado por profissionais da SEEDUC ao lado da SEAP o Plano Estadual de Educação em Cadeias no estado carioca, mas infelizmente o projeto não foi legalizado. Ainda em 2010, o Estado promove uma reestruturação transformando a COESP em DIESP (Diretoria especial das Escolas Socioeducativas e Prisionais), ainda vinculada a Secretaria de Educação (SEEDUC). De acordo com Diório (2017), SEEDUC e SEAP celebraram em 2011 um Marco de Cooperação Técnica entre as duas secretarias, que tinha como objetivo ofertar a Educação básica dentro da própria Secretaria de Administração Penitenciária. Este marco presume distintos conceitos e ações voltados para trazer melhorias para a própria educação prisional e neste documento a SEEDUC deixa claro o seu empenho em levar educação básica a todos os presídios conforme a Lei 9394/96. Por sua vez, a SEAP comprometeu-se a edificar espaços destinados à escola nas Unidades Prisionais.

Hoje em dia todos os colégios que funcionam dentro de presídios são geridos pela SEEDUC. Fazem parte o 1ํ e 2o segmento do Ensino Fundamental e Ensino Médio, na modalidade de Educação de Jovens e Adultos (EJA), que é ofertada na forma presencial e semipresencial conforme a necessidade da própria Unidade prisional e a capacidade da escola. A maior parte dos colégios encontram-se no complexo de Gericinó em Bangu conforme disposto na tabela abaixo.

Tabela 1: Escolas Complexo Gericinó

\section{Escolas Complexo Gericinó}


C.E. Angenor de Oliveira - Cartola

Penitenciária Industrial Esmeraldino

Bandeira

C.E. Escritor e Jornalista Graciliano Instituto Penal Plácido Sá de Carvalho Ramos

C.E. Evandro João da Silva

Penitenciária Serrano Neves

C.E. Henrique de Souza Filho - Henfil

Penitenciária Vicente Piragibe

C.E. José Lewgoy

Penitenciária Moniz Sodré

C.E. Mário Quintana

Penitenciária Lemos Brito

C.E. Padre Bruno Trombetta

Presídio Elizabeth Sá Rego

C.E. Prof. Alda Lins Freire

Penitenciária Alfredo Tranjan

C.E. Prof ${ }^{a}$ Sônia Ma Menezes

Penitenciária Jonas Lopes

C.E. Prof. Carlos da Costa

Penitenciária Gabriel Ferreira Castilho

C.E. Roberto Burle Marx

Penitenciária Talavera Bruce

C.E. Rubem Braga

Instituto Penal Benjamin de Moraes

Filho

C.E. 1 a Tenente PM Hailton dos Santos

Presídio Nelson Hungria

C.E. José Lewgoy (anexo)

Cadeia Pública Joaquim Ferreira de Souza

NACES- Núcleo Avançado de Centro Penitenciária Joaquim Ferreira de de Ensino Supletivo Souza

C.E. Prof. Carlos da Costa (anexo)

Cadeia Pública Bandeira Stampa Isoladas
C.E. Anacleto de Medeiros
Presídio Evaristo de Moraes

Niterói

C.E. Professor Carlos da Costa (anexo) Penitenciária Vieira Ferreira Neto Magé

C.E. Professor Carlos da Costa (anexo) Colônia Agrícola Marco Aurélio Vergas Tavares de Mattos

C.E. Professor Carlos da Costa (anexo) Presídio Hélio Gomes Japeri

Disponível em: https://www.nucleodoconhecimento.com.br/administracao/educacao-como- 


\section{C.E. Carlos Pereira Guimarães Filho Cadeia Pública Cotrim Neto (anexo)}

C.E. Carlos Pereira Guimarães Filho Penitenciária Milton Dias Moreira (anexo)

C.E. Luiz Gama (a inaugurar)

Penitenciária Milton Dias Moreira

C.E. Carlos Pereira Guimarães

Presídio João Carlos da Silva

Campos dos Goytacazes

C.E. Padre Bruno Trombetta (anexo) Presídio Nilma da Silva Santos

C.E. Padre Bruno Trombetta

Presídio Carlos Tinoco da Fonseca

C. E. Padre Bruno Trombetta (anexo) Cadeia Pública Dalton Crespo Itaperuna

C.E. Padre Bruno Trombetta

Presídio Diomedes Vinhosa Muniz

Volta Redonda

C. E. Padre Bruno Trombetta (anexo) Cadeia Pública Franz de Castro Holzwarth

Fonte: http://visitanteseap.detran.rj.gov.br

Apesar da quantidade de unidades que contam com escolas instaladas serem expressivas, quando olhamos para os dados não parecem ser produtivos. De acordo com dados do SISDEPEN que é a plataforma de estatísticas do sistema penitenciário brasileiro, os dados fornecidos pelos estabelecimentos penais cariocas no período de janeiro a junho de 2020, a população carcerária envolvida em atividade educacional é mínima considerada o conjunto da população carcerária carioca que no período era de 48708 presos e presas. Ainda segundo SISDEPEN, apenas 1770 internos estavam envolvidos em alguma atividade educacional no período: $511 \mathrm{em}$ atividade de alfabetização; 596 no ensino fundamental; 311 no ensino médio; 06 no ensino superior; apenas 02 em cursos profissionalizantes e 344 em atividades de remição pelo estudo e esporte. Esses números representam 3,63\% da população carcerária apenas que estavam envolvidos em alguma atividade educativa. 


\subsection{A ESCOLA PRISIONAL: FUNCIONAMENTO E MODALIDADE DE ENSINO}

O funcionamento de uma escola no ambiente prisional é diferenciado em relação a uma escola convencional. Essa diferenciação se dá devido às especificidades do público atendido. Entretanto, mesmo com essas distinções, os internos são tratados com respeito e dignidade humana para que possam sentir-se como alunos. Porém, são cobradas aos alunos atitudes e condutas para que possam estar habilitados a frequentarem as aulas. Devem apresentar um bom comportamento, estarem asseados com o cabelo cortado e a barba feita, trajados com roupas apropriadas. Além da obediência formal às regras estabelecidas pela unidade, os internos obedecem a regras informais impostas pelos próprios internos.

Por outro lado, os professores também possuem algumas condutas a observar. Estes devem sempre utilizar um guarda pó ou jaleco, principalmente as mulheres. Isso evitaria chamar a atenção dos internos para as professoras. O uso de saias curtas, bermudas e qualquer peça de vestuário feminino que mostre partes do corpo das professoras deve ser evitado. (MORAES, 2011, p. 60)

Para adentrar na escola, o profissional docente segue um rito completamente diferenciado comparado a escola formal. Para se ter acesso a uma unidade prisional, são necessárias algumas medidas cautelares para não comprometer a segurança da unidade, objetos como câmeras fotográficas, celulares etc. não são permitidos entrar para o interior da unidade. Todos que adentram a unidade passam por revista, podendo ser utilizado detector de metal para tal procedimento. Os docentes e funcionários da escola em geral precisam fazer a sua parte. Não devem conversar sobre nada que não seja de cunho pedagógico. Contato físico não pode existir, principalmente se a profissional for mulher.

A maioria das escolas possui mais de três salas de aula e não mais que dez salas. As escolas possuem, também, pequenas bibliotecas com acervo razoável de livros em virtude do programa de aquisição de livros conhecido como Feira do Livro, implantado pela SEEDUC, e em alguns casos laboratório de informática equipado com computadores não ligados à rede. (JULIÃO, 2012, p. 76) 
A merenda oferecida pela escola é diferente da ofertada do lado de fora, apenas lanches podem ser oferecidos, ficando as refeições ao encargo do Sistema Prisional.

As escolas prisionais oferecem a modalidade presencial de ensino supletivo conhecida como EJA (Educação de Jovens e Adultos), podendo também oferecer a educação profissional e tecnológica numa matriz criada específica para o sistema prisional, distribuídas em 03h de aulas diárias em cada turno (manhã e tarde) assim, a cada quatro dias de aulas presenciais o interno terá um dia a remir de sua pena. Os estudantes são inscritos a partir dos anos iniciais até os finais do Ensino Médio. Infelizmente $o$ analfabetismo e baixa escolaridade são uma triste realidade no sistema prisional.

Reforça-se a necessidade de desenvolvimento de políticas públicas voltadas para esse grupo. Fortalecendo e criando oportunidades para que possam - dependendo de quanto tempo permanecerem presos - conseguir sair pelo menos com a educação básica concluída e quem sabe melhores preparados para o convívio em sociedade. Para Craidy (2010) "[...] na educação as aulas acabam sendo precárias no que tange a motivar os presos, que na maior parte das vezes não se interessam, estão mais ali para remir a pena ou quem sabe sair de dentro das celas apertadas".

\subsection{A LEGISLAÇÃO}

A pessoa quando presa não perde o direito à educação. Esse direito está previsto na Constituição Federal de 1988 no seu Art. 205 ao afirmar que é um direito de todos e dever do Estado. A educação permite que o sujeito busque a efetivação dos direitos, desenvolvimento pessoal, exercício da cidadania.

É direito do preso o acesso à escola e deve ser exigido. Dessa forma é preciso que esse direito seja de fato garantido, pois não depende em hipótese alguma de sua qualidade social ou da posição civil.

Conforme plano normativo nacional, o acesso à escola dentro das cadeias brasileiras deve seguir as especificidades da Educação de Jovens e Adultos (EJA). Essa 
especificidade tem como escopo principal que o sujeito que não possui possibilidade de ingressar ou dar sequência aos estudos na idade concernente deve ter direito à esta modalidade. A LDB disciplina que segundo conjecturado no último texto constitucional, todos os sujeitos devem ter acesso ao Ensino Fundamental indispensável e gratuito, garantido, até mesmo, aos que não tiverem como ingressar na idade competente.

A Lei da Execução Penal ํo 7.210 de 1984, além de efetivar as disposições de sentença ou decisão criminal, tem como objetivo a harmônica integração social do condenado e do internado. A lei elucida que é dever do Estado a prestação de assistência ao preso, que esta será material, à saúde, religiosa, social, educacional e jurídica. A prestação da assistência ao preso objetiva prevenir o crime e prepará-los para o retorno ao convívio social.

A educação, em síntese, conforme os nossos marcos legais, é um direito público e subjetivo e sua oferta escolar deve estar adequada às necessidades e disponibilidades dos seus sujeitos, garantindo sob qual quer coisa, condições de acesso e permanência na escola (JULIÃO, 2015).

Sabe-se que a lei precisa ser aplicada, mas é preciso lembrar que o contexto local precisa ser levado em consideração e as suas próprias leis. Contudo, precisa-se considerar alguns fatores. Primeiramente a falta de informação dos funcionários dos Órgãos prisionais acerca do conteúdo dos documentos educacionais. Estes últimos são muito dinâmicos, sofrem alteração a todo momento e por isso seria necessário esse melhor acesso. Esse ponto de fragilidade é muito sério, uma vez que possibilita conflitos entre escola e Unidade prisional quanto a fazer valer certos direitos. Além disso, Rodrigues (2011) aponta a questão dos rumos que demonstram como funciona a escola prisional e a necessidade de adaptações para que se cumpra a lei. $O$ decreto federal 7.626, de 24 de novembro de 2011 que institui o Plano Estratégico de Educação no âmbito do Sistema Prisional e que tem como uma de suas diretrizes a educação como meio de promover a reintegração social da pessoa privada de liberdade. 


\title{
2.4 QUESTÕES PERTINENTES À RESSOCIALIZAÇÃO
}

Compete observar que a maior parte dos estados têm ação independente, porém quase sempre não são atuações institucionalizadas. Isso acontece porque quase sempre são planos que não têm extensa permanência e por conta disso não atendem muitas pessoas. Existem casos de estados que não conseguem sequer exercer o que a legislação determina que é ter um espaço mínimo para que a escola possa funcionar.

Infelizmente o Estado brasileiro está longe de fazer o básico pela educação. A situação ainda é mais complicada quando o assunto é a oferta para a população carcerária. Os presos têm direito à escola, mas o Estado parece se preocupar só com a criação de vagas para alojar o número cada vez maior de apenados, esquecendose que a ressocialização também é um objetivo a ser alcançado, uma forma de prevenir e reduzir a reincidência criminal por meio da facilitação do acesso à educação.

A educação é um instrumento de transformação, que pode proporcionar ao indivíduo capacidade de mudar e transformar a realidade em que ele está inserido, pode ainda atingir objetivos imediatos como aponta Julião.

\begin{abstract}
Manter os reclusos ocupados de forma proveitosa; melhorar a qualidade de vida na prisão; e conseguir um resultado útil, tal como ofícios, conhecimentos, compreensão, atitudes sociais e comportamento, que perdurem além da prisão e permitam ao apenado o acesso ao emprego ou a uma capacitação superior, que, sobretudo, propicie mudanças de valores, pautando-se em princípios éticos e morais. (JULIÃO, 2016, p. 34).
\end{abstract}

\section{PROCEDIMENTOS METODOLÓGICOS}

A pesquisa foi produzida pela forma qualitativa, fez-se pela maior importância de um material mais seleto que dados numéricos, gráficos e estatísticas. Utilizou-se de variados autores e teses para realizar a crítica sobre o tema escolhido. O objetivo é de cunho exploratório visto que foi aprofundado o tema das diversas bibliografias 
escolhidas, para dessa forma selecionar os patês que mais importariam. Desse mesmo modo, os questionamentos elencados foram de cunho exploratório, pois optou-se em respondê-los também com base na bibliografia.

\section{APRESENTAÇÃO E DISCUSSÃO DOS RESULTADOS}

Apesar do sistema prisional apresentar diversos problemas em relação à escola, acredita-se que de alguma forma sempre irá ser produtivo o trabalho realizado pela escola na formação dos indivíduos. Sendo assim, independente do que ocorra uma coisa que sempre permanecerá é o conhecimento adquirido. Como Julião disse em sua tese, um dos objetivos imediatos das escolas prisionais é justamente a ressocialização.

Percebe-se que os professores precisam de uma rede de apoio completa, sendo necessário um treinamento adequado, e uma formação continuada para que se possa aprimorar o trabalho. No texto de Craidy (2010), é possível ver alguns desses problemas que a escola enfrenta. Tais como as condições precárias, que tornam tudo mais difícil. Muitas vezes o presidiário perde a vontade em aprender, se fazendo presente apenas para cumprir as horas. Ao longo da discussão pudemos ver mais claramente como essas ferramentas para auxílio não existem. E em relação aos profissionais, eles se veem obrigados a dar aula apenas com a cara e a coragem, precisando se adaptar às dificuldades encontradas no dia a dia para que possam superá-las e dar continuidade na formação dessas pessoas.

Como foi salientado anteriormente, a educação escolar não deve ser a única responsável pela ressocialização do preso, mas é um instrumento fundamental para reconduzi-lo à sociedade, através da construção de um elo para uma nova forma de viver. O próprio decreto 7.626/2011 traz como uma das diretrizes a reintegração.

\section{CONSIDERAÇÕES FINAIS}

Para o sentenciado, a escola possui um leque de possibilidades para a mudança da sua realidade. Por exemplo, para uma pessoa presa, a sala de aula é um contraponto

Disponível em: https://www.nucleodoconhecimento.com.br/administracao/educacao-como- 
onde se fala de cidadania, de trabalho, de ressocialização e outros assuntos que dizem respeito à Seara Prisional. Entretanto, a falta de apoio, tempo e investimento fazem com que as escolas não sejam tratadas com a real importância que possuem. A escola torna possível, mesmo que de forma muito limitada, a possibilidade de repensar algumas questões. Além de tornar possível a conclusão dos estudos e o recebimento de um diploma, que não foi possível além muros até então.

Percebe-se que há muito a se modificar quanto à educação dentro das cadeias. É ainda um assunto repleto de vulnerabilidade. Mesmo com seus problemas, e com alcance ainda restrito, existe muito aproveitamento das oportunidades geradas. Os professores e profissionais que tornam isso possível, em geral possuem uma enorme vontade de fazer a diferença na vida desses presidiários, tornando realidade a mudança e fazendo muitas as histórias se tornarem um sucesso. Muitas pessoas nem imaginam que é legal o direito à escola para os presos. Isso se deve ao fato de que ainda é um tema com muito tabu envolvido e que precisa ter mais visibilidade, já que a ideia dentro do ambiente prisional é justamente a ressocialização.

A escola dentro dos presídios possui um propósito mais amplo do que apenas levar o conhecimento e preparar melhor o presidiário para o mercado de trabalho quando receber a liberdade. Por de trás das grades, encontram-se pessoas quase sempre estigmatizadas pela sociedade. O estigma é um sinal contraproducente que acaba afetando não o indivíduo, mas o coletivo que alimenta a discriminação e o preconceito. Todos esses elementos não corroboram para os presos enxergarem motivos para desejarem mudança em seu estilo de vida quando estiverem com suas penas pagas. Ou seja, além de ficarem afastados do convívio social para se redimirem por seus atos, ainda são julgados fora das prisões e vivem com uma "mancha" que na maioria das vezes os impede de ter um retorno e uma mudança eficazes. A escola age no sentido de mostrar que todos merecem esse direito de mudar.

A escola não cala aqueles detentos. Isso porque dentro da escola são tratados como alunos, e não presidiários. Tornando esses indivíduos capazes de mostrarem habilidades que nem eles sabiam que tinham, e acima de tudo resgatar ou construir 
um vínculo com a escola. Dentro do colégio não existe a pena e a punição, mas sim uma relação entre a educação e a probabilidade de alcançar o desenvolvimento pessoal. Através dessa dissertação, nota-se que o aprendizado nas escolas prisionais está diretamente ligado à ressocialização, e ao preparo para o mercado de trabalho. Mas acima de tudo propiciar a valorização individual e social em prejuízo do estigma do cárcere.

A educação serve como um instrumento potencializador que prepara o homem, com a forma necessária para exercer atividades funcionais adequadas. Contudo, confirmase que esse espectro pragmático da educação escolar, entre a maior parte dos presos, é produto de uma visão ideológica que não idealiza a educação como direito, aspecto que impede a organização para a exigência desse direito. Tal visão também confirma a obrigação de articulação da educação com todas as políticas públicas voltadas para as questões prisionais a fim de permitir um formato sistemático e potencializador da educação.

No entanto, esse trabalho não esgota o debate, espera-se que possa contribuir com o assunto, bem como a necessidade de reflexão e ampliação de tal tema que se mostra inadiável devido a ascensão da massa carcerária.

\section{REFERÊNCIAS}

ASSESSORIA DE COMUNICAÇÃO SOCIAL. "Há 726.712 pessoas presas no Brasil". Jus Brasil. Disponível em: https://www.justica.gov.br/news/ha-726-712pessoas-presas-no-brasil. Acesso em: 23/03/2021.

BRASIL. Ministério da Saúde. Secretaria de Atenção à Saúde. Departamento de Ações Programáticas Estratégicas. Plano Nacional de Saúde no Sistema Penitenciário / Ministério da Saúde, Secretaria de Atenção à Saúde, Departamento de Ações Programáticas Estratégicas. $2^{\underline{a}}$ ed. Editora do Ministério da Saúde. Brasília, 2015. 
CARRREIRA, Denise. Relatoria nacional para o direito humano à educação: educação nas prisões brasileiras. São Paulo: Plataforma DhESCA Brasil, 2009. Disponível em:

http://www.dhescbrasil.org.br/attachments/289_Educa\%C3\%A7\%C3\%A30\%20n as\%20pris\%C3\%B5es\%20do\%20Brasil.pdf >. Acesso em: 10/08/2020.

COSTA, Antônio Carlos Gomes da. Socioeducação: estrutura e funcionamento da comunidade educativa. Secretaria Especial de Direitos Humanos. Brasília, 2013.

CRAIDY, Carmem Maria (org). Educação em prisões: direito e desafios.: UFRGS Porto Alegre, 2010.

Declaração Universal Dos Direitos Humanos. UNIC/RIO/005. Janeiro, 2009 DIORIO, Tatiane Almeida. Entre o ensino e a ressocialização: práticas de professores de ciências na educação prisional masculina no município do Rio de Janeiro. PUC - Rio de Janeiro, 2017.

DOTTI, René Ariel. A crise do sistema penitenciário. 2003.

FOUCALT, Michel. Vigiar e Punir: o nascimento da prisão. Tradução de Raquel Ramalhete. 29å. ed. Editora Vozes. Petrópolis, 1979.

GOFFMAN, Erving. Manicômios, Prisões e Conventos. Trad. Dante Moreira Leite. 7.ed. Editora Perspectiva. São Paulo, 2001.

GOMES, L.F. “Noruega como modelo de reabilitação de criminosos”. Jus brasil, 2013. Disponível em: https://professorlfg.jusbrasil.com.br/artigos/121932086/noruegacomo-modelo-de-reabilitacao-de-criminosos. Acesso em: 23/03/2021.

HADDAD, Sérgio. Os desafios da educação escolar e não escolar nas prisões. In: YAMAMOTO, Aline et al (org.). Educação em prisões. Alfasol, Cereja. São Paulo, 2014. 
JULIÃO, Elionaldo Fernandes. Política pública de educação penitenciária: contribuição para o diagnóstico da experiência do Rio de Janeiro. Dissertação (Mestrado) - Departamento de Educação, Pontifícia Universidade Católica do Rio de Janeiro. Rio de Janeiro, 2003.

Sistema penitenciário brasileiro: a educação e o trabalho na política de execução penal. Petrópolis: De Petrus et Al. 2012.

LEMGRUBER, Julita. Cemitério dos vivos: análise sociológica de uma prisão de mulheres. Forense. Rio de Janeiro, 1999.

MELO, Vanusa Maria de; Duarte, Rosália Maria. Aproveitando brechas: experiências com cinema em escolas prisionais do Rio de Janeiro. 139 p. Dissertação de Mestrado. Departamento de Educação, Pontifícia Universidade Católica do Rio de Janeiro. Rio de Janeiro, 2014.

MORAES, Pedro R. Bode. A retórica e a prática da ressocialização em instituições prisionais. Grupos de Estudos da Violência - UFPR. Curitiba, 2011.

RODRIGUES, Alvino Augusto. A "ressocialização" de presos e a terceirização de presídios: impressões colhidas por um psicólogo em visita a dois presídios terceirizados. $2011 . \quad$ Disponível em: < http://www.escolamp.org.br/arquivos/21_01.pdf >. Acesso em 24/08/2019.

RODRIGUES, Anabela Miranda. Novo olhar sobre a questão penitenciária: estatuto jurídico do recluso e socialização, jurisdicionalização, consensualismo e prisão. [s.e.]. Revista dos Tribunais. São Paulo, 2011.

SABADELL, Ana Lúcia. Algumas reflexões sobre as funções da prisão na atualidade e o imperativo da segurança. In: OLIVEIRA, Rodrigo Torres; MATTOS, Virgílio (Orgs.). Estudos de execução criminal: direito e psicologia. TJMG/CRP. Belo Horizonte, 2009.

SILVA JÚNIOR, Walter Nunes da. O Direito Penal e a Criminalidade. 2012.

Disponível em: https://www.nucleodoconhecimento.com.br/administracao/educacao-como- 
VALDEJÃO, Renata. Prisões: lotadas e falidas, as cadeias brasileiras não isolam nem recuperam os criminosos. Revista Super Interessante, Edição Especial: Segurança. Editora Abril. São Paulo, 2002.

VASCONCELOS, Ana S. F. A saúde sob custódia: Um estudo sobre agentes de segurança penitenciária no Rio de Janeiro. Dissertação (mestrado). Escola Nacional de Saúde Pública, Fiocruz. Rio de Janeiro, 2012.

Enviado: Abril, 2021.

Aprovado: Junho, 2021. 